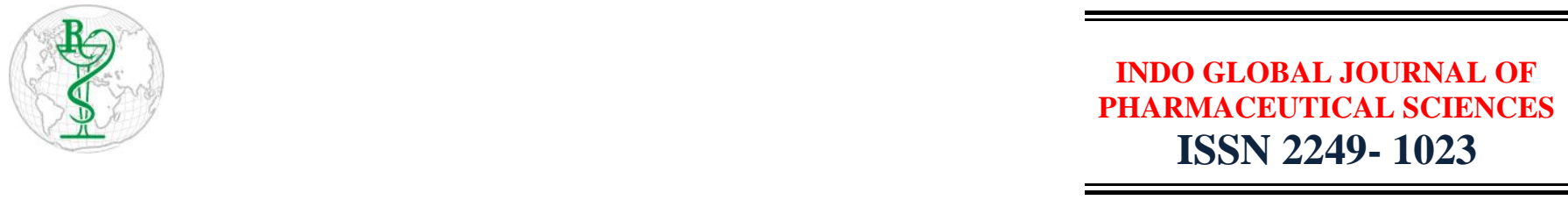

\title{
Role of Antioxidant in Preparation of Metallic Nanoparticles
}

\author{
Gurmandeep Kaur *, Yogita Kumari, Clarisse Ayinkamiye, Sachin Kumar Singh, Rajesh Kumar, \\ Rubiya Khursheed
}

School of Pharmaceutical Sciences, Lovely Professional University, Phagwara -144411, Punjab, India

Address for Correspondence: Gurmandeep Kaur; gurmandeep095@gmail.com

\begin{tabular}{l} 
Received: \\
01.03.2019 \\
Accepted: \\
25.03.2019 \\
Keywords \\
Metallic \\
Nanoparticles; \\
Antioxidants; \\
Green Method. \\
\hline
\end{tabular}

Received:

Accepted:

Keywords

Metallic

Antioxidants;

Green Method.

\begin{abstract}
The preparation of metallic nanoparticles involves reduction of the metal ion using turkevich, burst, chemical, physical and sonochemical methods. Green method has drawn great attention as compared to physical and chemical methods because it was found to be more energy efficient and able to eliminate the use of hazardous chemicals. The phytoconstituents that are used to synthesize the nanoparticles are known to be rich in polyols and antioxidants. Antioxidants like enzymatic and non-enzymatic substances which are involved in management of free radical formation, also act as stabilizing as well as reducing agent in the preparation of nanoparticles. The reduction mechanism is also capable to control the size and stability of synthesized nanoparticlesby formation of stable bonding between metallic nanoparticles and phytochemicals present in leaf extract. In the current presentation various plant extracts and isolated phytoconstituents used for synthesis of metallic nanoparticles are discussed. (C) 2019 iGlobal Research and Publishing Foundation. All rights reserved.
\end{abstract}

Cite this article as: Kaur, G.; Kumari, Y.; Ayinkamiye, C.; Singh, S.K.; Kumar, R.; Khursheed, R. Role of Antioxidant in Preparation of Metallic Nanoparticles. Indo Global J. Pharm. Sci., 2019; 9(2Suppl.): 122. DOI: http://doi.org/10.35652/IGJPS.2019.92S20.

Indo Global Journal of Pharmaceutical Sciences( ISSN 2249 1023; CODEN- IGJPAI; NLM ID: 101610675) indexed and abstracted in CrossRef (DOI Enabling), UGC CARE Journal List, EMBASE(Elsevier), National Library of Medicine (NLM) Catalog, ResearchGate, Publons, CAS (ACS), Index Copernicus, Google Scholar and many more. For further details, visit http://iglobaljournal.com

This is a special issue as an outcome of 'RAPSCON-2019' sponsored by APTI and organized by Sri Sai College of Pharmacy, Manawala, Amritsar, Punjab, India. Relaxation offered in journal format. 